\title{
ULTRAESTRUCTURA DENDRÍTICA EN NEURONAS PIRAMIDALES DE RATONES INOCULADOS CON VIRUS DE LA RABIA
}

\author{
Orlando Torres-Fernández ${ }^{1}$ \\ Jeison Alexander Monroy-Gómez² \\ Ladys Esther Sarmiento Lacera ${ }^{3}$
}

\section{RESUMEN}

Objetivos: Estudiar el efecto de la infección con rabia sobre la ultraestructura dendrítica de las neuronas piramidales de la corteza cerebral en ratones inoculados con el virus por vía intramuscular. Métodos: Ratones adultos inoculados con el virus de la rabia y ratones inoculados con solución vehículo sin el virus (controles) fueron fijados por perfusión intracardiaca, con una solución que contenía paraformaldehído al $4 \%$ y glutaraldehído al 2\%, cuando los animales infectados manifestaron signos avanzados de la enfermedad. Los encéfalos fueron extraídos y cortados en plano coronal en un vibrátomo. Fragmentos pequeños y delgados de estos cortes, que contenían el área de la corteza cerebral motora, fueron procesados para microscopía electrónica de transmisión. Resultados: En las dendritas distales de las neuronas piramidales de los animales controles se observaron mitocondrias largas y estrechas, así como abundantes microtúbulos organizados en paralelo con la membrana celular.
En las dendritas distales de las neuronas piramidales de los ratones infectados con el virus se observaron unas estructuras electrodensas de forma irregular semejantes a figuras de mielina, pero no se observaron las mitocondrias alargadas y los microtúbulos fueron escasos. Algunas dendritas también exhibieron la formación de vacuolas que interrumpían la continuidad del citoplasma y los microtúbulos. Conclusión: La infección con virus de la rabia generó cambios ultraestructurales en las dendritas de las neuronas piramidales corticales que aparentemente no se conocían. Estos resultados son coherentes con hallazgos previos, usando otras técnicas y modelos experimentales, en donde se ha demostrado patología dendrítica inducida por la infección con rabia.

Palabras clave: virus de la rabia, patología dendrítica, figuras de mielina, microtúbulos, neuronas piramidales, ultraestructura del sistema nervioso.

\footnotetext{
${ }^{1}$ Doctor en Ciencias Biomédicas. Laboratorio de Microscopía, Grupo de Morfología Celular, Instituto Nacional de Salud (INS). Bogotá, Colombia. Autor para correspondencia. Correo electrónico: otorresf@ins.gov.co ID ORCID: 0000-0001-6620-2615 2 Especialista en Proyectos de Investigación Científica y Tecnológica - Estudiante de Maestría en Neurociencias. Laboratorio de Microscopía, Grupo de Morfología Celular, Instituto Nacional de Salud (INS). Bogotá, Colombia. Correo electrónico: jeison-onroy@hotmail.com iD ORCID: 0000-0001-9765-0461

${ }^{3}$ Magíster en Microbiología. Laboratorio de Microscopía, Grupo de Morfología Celular, Instituto Nacional de Salud (INS). Bogotá, Colombia. Correo electrónico: Isarmiento@ins.gov.co iDORCID: 0000-0002-7693-6206
} 


\section{DENDRITRIC ULTRASTRUCTURE ON PYRAMIDAL NEURONS OF MICE INOCULATED WITH RABIES VIRUS}

\section{ABSTRACT}

Objectives: To study the effect of rabies infection on the dendritic ultrastructure of pyramidal neurons in the cerebral cortex of mice intramuscularly inoculated with rabies virus. Methods: Adult mice inoculated with rabies virus and mice inoculated with vehicle solution without the virus (controls) were fixed by intracardiac perfusion with a solution containing $4 \%$ paraformaldehyde and $2 \%$ glutaraldehyde. When infected animals showed advanced signs of disease, their brains were extracted and cut into the coronal plane on a vibratome. Small and thin fragments of these cuts containing motor cortex area were processed for transmission electron microscopy.

\section{INTRODUCCIÓN}

La rabia es una enfermedad infecciosa causada por un virus que afecta principalmente al sistema nervioso central. El virus es introducido en las fibras musculares mediante la mordedura de un animal infectado. Las partículas virales liberadas por la saliva ingresan a través de la placa neuromuscular y por transporte axonal retrógrado son conducidas hasta la médula espinal y luego al encéfalo (1). Previamente nosotros encontramos evidencia de que el virus de la rabia llega primero a la corteza cerebral a través de las neuronas piramidales de la capa $V$ en ratones inoculados en músculos de las extremidades posteriores $(2,3)$. La vulnerabilidad de las neuronas piramidales corticales a la infección con rabia también se ha demostrado mediante la técnica de Golgi que ha revelado alteraciones notables en la morfología dendrítica (4). Otros autores también
Results: Distal dendrites of pyramidal neurons of control animals showed long and narrow mitochondria and abundant microtubules arranged in parallel with the cell membrane. In distal dendrites of pyramidal neurons of rabiesinfected mice some irregular shape electrondense structures similar to myelin figures were observed but elongated mitochondria were not observed, and microtubules were scarce. Some dendrites also exhibited vacuole formation interrupting the continuity of cytoplasm and microtubules. Conclusion: Infection with rabies virus produced ultrastructural changes within dendrites of the cortical pyramidal neurons that apparently were not known. These results are consistent with previous findings using other techniques and experimental models where it has been shown dendritic pathology induced by infection with rabies.

Key words: rabies virus, dendritic pathology, myelin figures, microtubules, pyramidal neurons, ultrastructure of nervous tissue.

han hallado evidencia de daño dendrítico causado por el virus de la rabia (5-7). Sin embargo, aunque se han llevado a cabo muchos estudios con microscopía electrónica del tejido nervioso infectado con rabia, estos casi no se refieren a la ultraestructura del árbol dendrítico. El análisis ultraestructural se ha enfocado más en las partículas virales (8-12) así como en la interpretación de los mecanismos celulares de transmisión del virus $(1,13,14)$. Este trabajo se realizó con el propósito de estudiar la estructura fina de las dendritas de las neuronas piramidales corticales en ratones inoculados con virus de la rabia por vía intramuscular.

\section{MÉTODOS}

Tres ratones ICR (Institute of Cancer Research) de 28 días de edad fueron inoculados con virus de la rabia obtenido a partir del cerebro de 
un perro infectado (virus de origen silvestre o tipo 'calle'). Cada animal fue inoculado en las extremidades posteriores a nivel de los músculos semimembranoso y semitendinoso con 0,03 ml de una alícuota de solución viral diluida $10^{-1}$ equivalente a $10^{6}$ LD50. Cuando los ratones alcanzaron un estado avanzado de la enfermedad, hacia los 10-12 días postinoculación (caracterizado por presentar pelo erizado, parálisis de las extremidades inferiores y pérdida de peso acentuada), fueron anestesiados con una inyección intraperitoneal de $1 \mathrm{ml}$ de hidrato de cloral al 30\%. A continuación fueron sometidos a perfusión intracardiaca inicialmente con tampón de fosfatos (PB) a $\mathrm{pH}$ 7,2 y luego con una solución de fijación compuesta por glutaraldehído al $2 \%$ y paraformaldehído al $4 \%$ preparada en PB. Con el mismo procedimiento se trataron dos ratones no inoculados con el virus (controles) de la misma edad que tenían los animales enfermos de rabia al momento de la perfusión (38-40 días). Este procedimiento fue avalado por el Comité de Ética del Instituto Nacional de Salud (INS, Colombia).

Los encéfalos fueron extraídos y cortados en plano coronal en un vibrátomo (Vibratome ${ }^{\circledR}$ ) para obtener rodajas de $200 \mu \mathrm{m}$ de espesor a nivel de la corteza frontal motora. Con las rodajas se realizó el procesamiento para microscopía electrónica mediante el siguiente protocolo: postfijación en tetróxido de osmio al 1\% durante 1 hora seguida de tres lavados en PB y deshidratación en etanol en concentraciones ascendentes $(50,70$, $80,90,95$ y 100\%). Luego las muestras (rodajas) fueron tratadas con óxido de propileno (OP) antes de iniciar la infiltración con mezclas de OP y resina Epón-Araldita (EA) (Polysciences) en proporciones secuenciales $2: 1,1: 1,1: 2$. A continuación las rodajas fueron embebidas en resina pura (EA) durante 12 horas y luego se extendieron en láminas portaobjetos pretratadas con una sustancia antiadherente. Sobre cada preparación secolocó otro portaobjetos para formar montajes tipo 'emparedado' que se colocaron dentro de un horno a $80^{\circ} \mathrm{C}$ durante 24 horas para polimerizar la resina con el tejido embebido.
Los montajes fueron separados con cuchillas de afeitar para exponer el tejido nervioso y seleccionar en un microscopio estereoscópico las áreas a estudiar con el microscopio electrónico. Fragmentos polimerizados de las rodajas de corteza, de no más de $1 \mathrm{~mm}^{2}$, fueron separados y pegados con cianocrilato sobre los extremos planos de bloques de resina previamente preparados. Este procedimiento permitió mantener la orientación de la corteza cerebral para obtener cortes sagitales de los árboles dendríticos de las neuronas piramidales. En un ultramicrótomo (LKB) se obtuvieron cortes semifinos (500 nm) que fueron coloreados con azul de toluidina para observarlos en el microscopio óptico. Se localizaron áreas con neuronas piramidales completas cortadas en un plano sagital de tal manera que pudiera observarse el soma y la dendrita apical. Estos campos se seleccionaron para obtener cortes ultrafinos $(60 \mathrm{~nm})$ que fueron recogidos en rejillas de cobre y contrastados con acetato de uranilo seguido de citrato de plomo. Las observaciones ultraestructurales se hicieron en un microscopio electrónico Zeiss EM 109. En bajo aumento (3000X), se localizaron las neuronas piramidales previamente seleccionadas en microscopía óptica y en mayor aumento (7000X - 20000X) se observaron, secuencialmente, los detalles ultraestructurales del soma, la dendrita apical y las ramas colaterales hasta su porción más distal (en adelante se llamarán dendritas distales). Se tomaron fotografías usando película TMAX (Kodak) y los negativos luego de ser revelados fueron escaneados para obtener las imágenes finales.

\section{RESULTADOS}

En el microscopio electrónico, una de las características más destacadas en la ultraestructura de las muestras de los ratones controles fue la presencia de mitocondrias abundantes, algunas de ellas muy alargadas, en las dendritas distales de las neuronas piramidales (Figura 1A). En mayor aumento se 
destacó dentro de las dendritas la imagen de los microtúbulos organizados en paralelo con la membrana celular (Figura 1B). En las muestras tomadas de los animales inoculados con virus de la rabia se hallaron notables alteraciones en la estructura fina de las dendritas distales de las neuronas piramidales. Se observó pérdida acentuada de microtúbulos y aquellos que se preservaron perdieron su orientación paralela y lucían desorganizados (figuras 2 y 3A). Además, las mitocondrias casi desaparecieron. La pérdida de mitocondrias y microtúbulos hizo que el citoplasma dendrítico luciera más claro.

Pero el hallazgo más notable en el material infectado con el virus de la rabia fue la presencia de numerosas estructuras membranosas y electrodensas dentro de las dendritas distales (figuras 2 y $3 \mathrm{~A}$ ) así como en algunos de los axones. Su tamaño osciló entre 0,5 y 1,25 micras $(n=15)$ y siempre se localizaron en el centro de las dendritas sin entrar en contacto con la membrana celular. Estas extrañas estructuras no fueron observadas en la dendrita apical ni en el soma de las neuronas piramidales. Las dendritas distales que las contenían eran más gruesas que en los controles, de contorno irregular y estaban desprovistas casi totalmente de mitocondrias y microtúbulos. Por otra parte, en los axones donde estuvieron presentes parecían inducir la formación de protuberancias. Adicionalmente, en algunas de las dendritas distales se observaron vacuolas que parecían interrumpir, parcial o totalmente, la continuidad del dendroplasma y los microtúbulos (Figura 3B). Por último, es importante destacar que en las dendritas distales afectadas no se observaron partículas virales ni cuerpos de Negri, estos solo fueron detectados en el soma y las dendritas apicales de las neuronas piramidales.

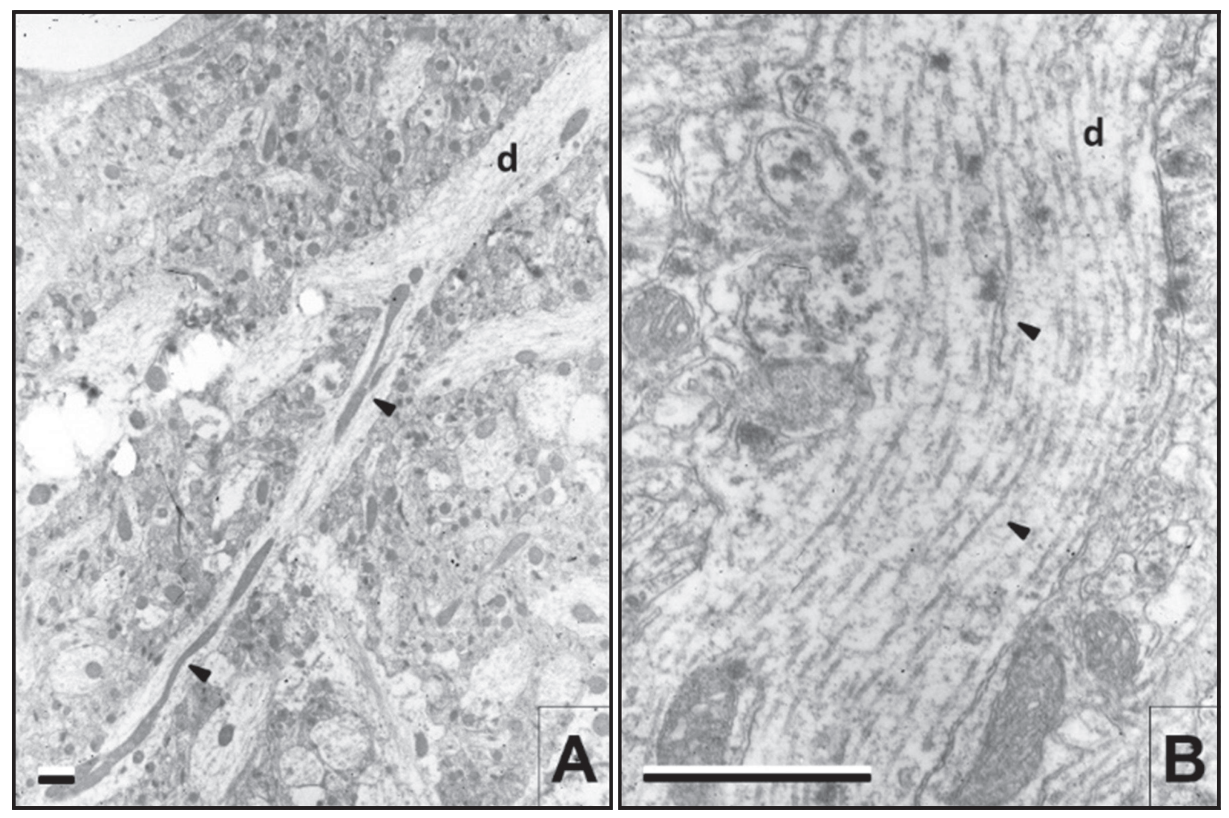

Escala de la barra $=1$ micrómetro

Figura 1. Fotografías tomadas, en el microscopio electrónico, de dendritas distales (d) de neuronas piramidales en un ratón control. A. Imagen panorámica de la bifurcación de una dendrita donde se observan mitocondrias delgadas y alargadas (cabezas de flecha). B. Detalle de un fragmento de dendrita con abundantes microtúbulos (cabezas de flecha) que mantienen su orientación paralela a la membrana celular. 


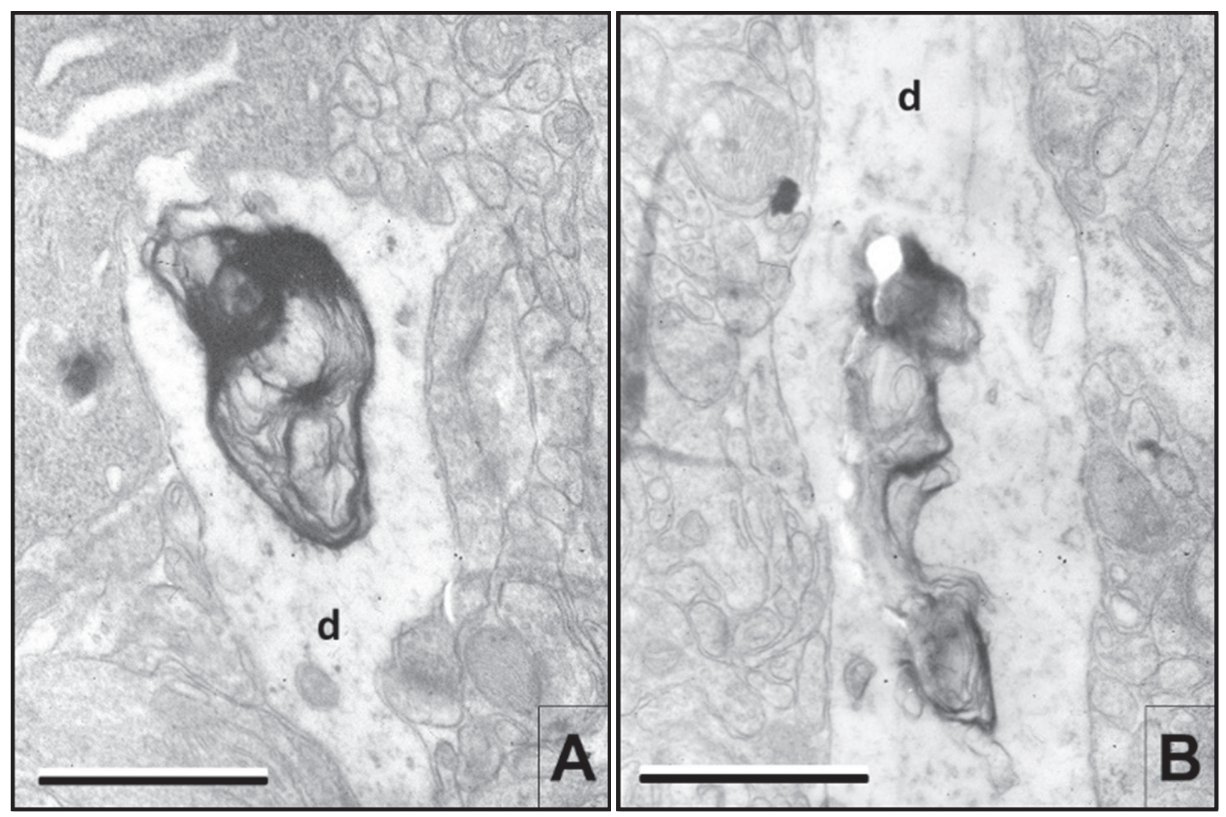

Escala de la barra = 1 micrómetro.

Figura 2. Dendritas distales (d) de neuronas piramidales en la corteza cerebral de un ratón infectado con rabia. Además de la ausencia de microtúbulos se destaca la presencia de unas grandes estructuras semejantes a figuras de mielina que contienen zonas electrodensas (oscuras) alternando con áreas de aspecto membranoso.

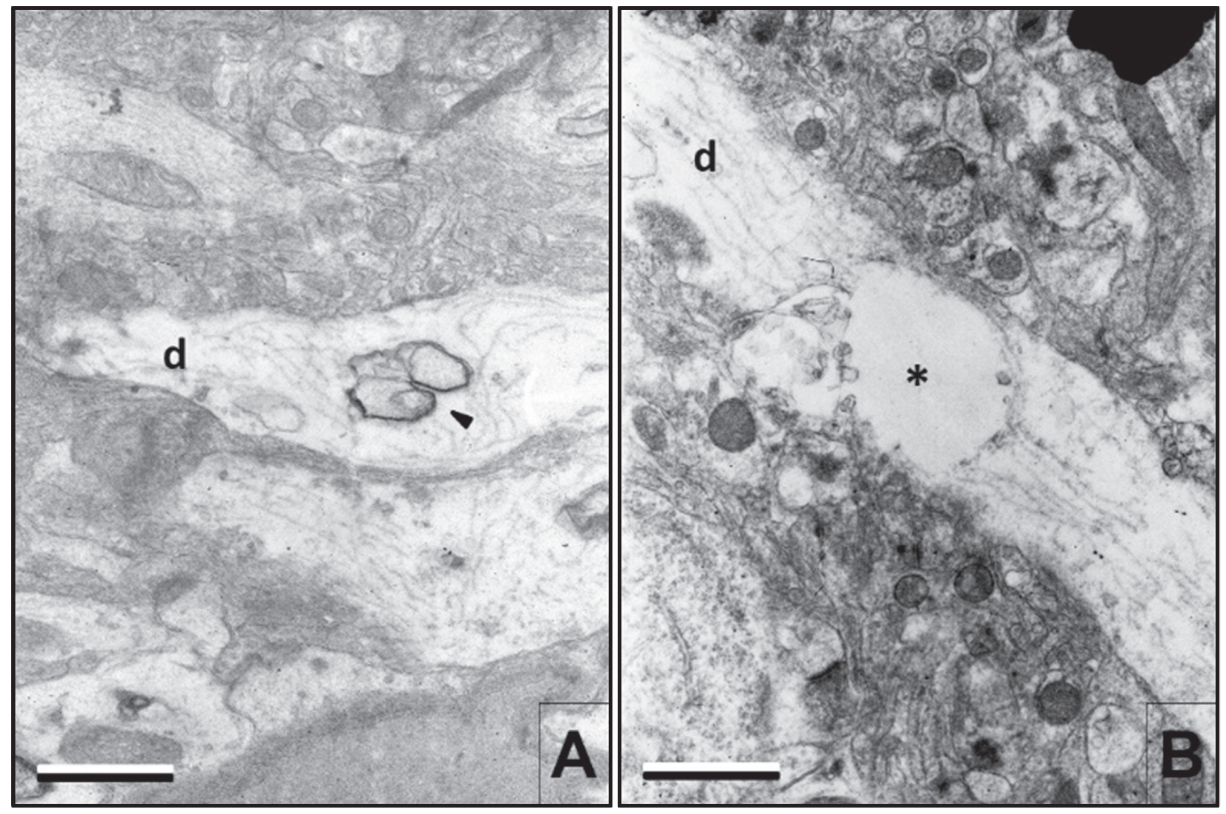

Escala de la barra = 1 micrómetro.

Figura 3. Dendritas distales (d) en la corteza cerebral de un ratón inoculado con rabia. En A se observa una figura de mielina (cabeza de flecha) rodeada de microtúbulos desorganizados. En $\mathbf{B}$ hay una gran vacuola $\left(^{*}\right)$ que interrumpe la continuidad del dendroplasma y los microtúbulos. 


\section{DISCUSIÓN}

Han sido numerosos los estudios realizados en microscopía electrónica del tejido nervioso afectado por rabia en muestras de casos humanos (14-17), animales domésticos y salvajes $(1,18,19)$, animales de laboratorio $(8,10-13)$ y cultivos celulares $(9,12,20)$. La gran mayoría de estos reportes hacen referencia a la morfología y localización intracelular de las partículas virales y los cuerpos de Negri. En menor proporción describen la ultraestructura de los componentes celulares de las neuronas, generalmente el pericarion. Pocos autores parecen haberse enfocado en observar la estructura fina de las dendríticas. Nosotros hemos procesado las muestras de tejido con un método que preserva la orientación del árbol dendrítico en paralelo con el plano de corte. Este procedimiento facilitó la observación de características ultraestructurales en las dendritas del tejido infectado que no habían sido reportadas anteriormente.

Mitocondrias estrechas y alargadas como las que observamos en las muestras control parecen ser una característica de las dendritas distales de las neuronas piramidales de la corteza cerebral (21). Es muy significativo que estos organelos no se hayan observado en las muestras de animales inoculados con el virus de la rabia. La escasez de mitocondrias, la marcada pérdida de microtúbulos así como la presencia de las raras estructuras electrodensas dentro de las dendritas distales de las células piramidales corticales en ratones infectados podrían estar relacionadas con la patología dendrítica previamente reportada $(4,22)$.

Nosotros creemos que esas estructuras electrodensas corresponden a lo que en patología ultraestructural en el idioma inglés se conoce como 'myelin-like figures' o simplemente 'myelin figures' (23-25) y que los libros de patología en español traducen como 'figuras de mielina'. También, consideramos que estas se derivan de la degeneración de las mitocondrias de acuerdo con los siguientes argumentos: 1) Las dendritas distales en el tejido no infectado con rabia contienen mitocondrias muy largas, mientras que en el tejido infectado estos organelos desaparecen y su lugar podría estar ocupado por las figuras de mielina. 2) Hay evidencia científica de que las figuras de mielina se forman a partir de la transformación de estructuras membranosas, principalmente de mitocondrias en repuesta a injuria celular (23-26). 3) Recientemente se ha reportado disfunción mitocondrial evaluada por métodos bioquímicos en células en cultivo infectadas con virus de la rabia (27).

Las figuras de mielina pueden también aparecer como resultado de artefactos derivados de las mitocondrias debido a fijación prolongada en glutaraldehído (28). Sin embargo, nosotros hemos iniciado el procesamiento de las muestras para microscopía electrónica inmediatamente después de la fijación con los aldehídos. Además, las figuras de mielina no se observaron en los controles. Por otra parte, la formación de figuras semejantes a mielina de origen patológico ha sido ampliamente documentada en diferentes tipos de tejidos $(23-26,29)$ y su origen mitocondrial se ha demostrado experimentalmente $(24,30)$. No obstante, las figuras de mielina que nosotros encontramos son diferentes en su morfología de las imágenes típicas de láminas concéntricas reportadas por otros autores $(24,29)$, incluyendo las figuras de mielina previamente observadas en el pericarion de neuronas de ratones infectados con rabia $(8,10)$. Las figuras de mielina descritas en este artículo son más electrodensas (oscuras), alargadas y de formas irregulares y no se encontraron dentro del pericarion.

Nuestros hallazgos ultraestructurales en las dendritas también difieren de los reportados por otros autores en procesos neuronales del tejido nervioso de ratones infectados con rabia. En un primer estudio se inocularon ratones por vía intracerebral con una variante patogénica (NC2) de virus 'fijo' CVS. La infección generó pérdida de organelos (mitocondrias y retículo endoplásmico), destrucción parcial de 
dendritas y menor electrodensidad en imágenes panorámicas (5). En un trabajo posterior realizado con ratones transgénicos inoculados por la ruta intramuscular con virus CVS, los autores describen hinchamiento de mitocondrias localizadas dentro del pericarion y el segmento proximal de las dendritas apicales de las neuronas piramidales pero los microtúbulos se conservaron intactos (6).

Para finaliza, debemos resaltar que la mayoría de estudios de patología experimental en rabia se han llevado a cabo utilizando un virus adaptado en laboratorio y conocido como virus 'fijo' (generalmente de la cepa CVS) e inoculado por vía intracerebral. Este modelo arroja resultados reproducibles en tiempos cortos y fijos. Nuestro experimento fue realizado con virus de origen silvestre, que se denomina 'calle' y fue inoculado por vía intramuscular. Este procedimiento se aproxima más a las condiciones naturales de la infección con rabia.
Se han descrito algunas diferencias en la patología inducida por los dos tipos de virus, incluyendo patología ultraestructural $(4,10,12)$.

\section{FINANCIACIÓN}

Este trabajo fue financiado con recursos del Departamento Administrativo de Ciencias, Tecnología e Innovación COLCIENCIAS y el Instituto Nacional de Salud (INS, Colombia). Proyecto Código 210454531601, Contrato 378 de 2011. La participación del segundo autor (JMG) fue financiada con beca del ‘Programa Jóvenes Investigadores'. Convenio COLCIENCIAS/INS 0237 de 2012.

\section{CONFLICTO DE INTERESES}

Los autores declaran no tener ningún conflicto de interés relacionado con este artículo.

\section{REFERENCIAS}

1. Schneider LG. Spread of virus within the central nervous system. In: Baer GM, ed. The nature history of rabies. New York: Academic Press; 1975. p. 199-216.

2. Torres-Fernández $\mathrm{O}$, Lamprea $\mathrm{N}$, Pimienta $\mathrm{H}$. Demostración del ingreso del virus de la rabia a la corteza cerebral a través de las neuronas piramidales de la capa V. Iatreia 2005; 18:S85-S86.

3. Lamprea N, Torres-Fernández O. Immunohistochemical evaluation of calbindin expression in mouse brain at different times after rabies virus inoculation. Colomb Med (Cali) 2008; 39(Suppl 3):7-12.

4. Torres-Fernández O, Yepes GE, Gómez JE. Neuronal dendritic morphology alterations in the cerebral cortex of rabies-infected mice: a Golgi study. Biomédica 2007; 27:605-13.

5. Li XQ, Sarmento L, Fu ZF. Degeneration of neuronal processes after infection with pathogenic, but not attenuated, rabies viruses. J Virol 2005; 79:10063-8.

6. Scott CA, Rossiter JP, Andrew RD, Jackson AC. Structural abnormalities in neurons are sufficient to explain the clinical disease and fatal outcome of experimental rabies in yellow fluorescent proteinexpressing transgenic mice. J Virol 2008; 82:513-21.

7. Song Y, Hou J, Qiao B, Li Y, Xu Y, Duan M, et al. Street rabies virus causes dendritic injury and F-actin depolimerization in the hippocampus. J Gen Virol 2013; 94:276-83.

8. Matsumoto S. Electron microscope studies of rabies virus in mouse brain. J Cell Biol 1963; 19:565-91.

9. Hummeler K, Koprowski H, Wiktor TJ. Structure and development of rabies virus in tissue culture. J Virol 1967; 1:152-70.

10. Miyamoto $\mathrm{K}$, Matsumoto $\mathrm{S}$. Comparative studies between pathogenesis of street and fixed rabies infection. J Exp Med 1967; 125:447-75. 
11. Matsumoto S. Electron microscopy of central nervous system infection. In: Baer GM, ed. The nature history of rabies. New York: Academic Press; 1975. p. 217-33.

12. Hummeler K, Atanasiu P. Electron microscopy. In: Meslin FX, Kaplan MM, Koprowski H, eds. Laboratory techniques in rabies. Geneva: World Health Organization; 1996. p. 209-17.

13. Iwasaki $Y$, Clark H. Cell to cell transmission of virus in the central nervous system: II. Experimental rabies in mouse. Lab Invest 1975; 33:391-99.

14. Iwasaki Y, Liu DS, Yamamoto T, Konno H. On the replication and spread of rabies virus in the human central nervous system. J Neuropathol Exp Neurol 1985; 44:185-95.

15. De Brito T, De Fátima M, Tiriba A. Ultrastructure of the Negri body in human rabies. J Neurol Sci $1973 ; 20: 363-72$.

16. Sandhyamani S, Roy S, Gode GR, Kalla GN. Pathology of rabies: a light- and electron-microscopical study with particular reference to the changes in cases with prolonged survival. Acta Neuropathol $1981 ; 54: 247-51$.

17. Manghani DK, Dastur DK, Nanavaty AN, Patel R. Pleomorphism of fine structure of rabies virus in human and experimental brain. J Neurol Sci 1986; 75:181-93.

18. Fekadu M, Chandler FW, Harrison AK. Pathogenesis of rabies in dogs inoculated with and Ethiopian rabies virus strain. Immunofluorescence, histologic and ultrastructural studies of the central nervous system. Arch Virol 1982; 71:109-26.

19. Charlton KM, Casey GA, Webster WA, Bundza A. Experimental rabies in skunks and foxes. Pathogenesis of the spongiform lesions. Lab Invest 1987; 57:634-45.

20. Velandia ML, Pérez-Castro R, Hurtado H, Castellanos JE. Ultrastructural description of rabies virus infection in cultured sensory neurons. Mem Inst Oswaldo Cruz 2007; 102:441-47.

21. Peters A, Palay S, Webster $\mathrm{H}$. The fine structure of the nervous system. Neurons and their supporting cells. 3rd ed. New York: Oxford University Press; 1991.

22. Hurtado AP, Rengifo AC, Torres-Fernández O. Immunohistochemical over expression of MAP-2 in the cerebral cortex of rabies-infected mice. Int J Morphol 2015; 33:465-70.

23. Sjöestrand FS, Cedergren EA, KarlssonU. Myelin-like figures formed from mitochondrial material. Nature $1964 ; 202: 1075-8$.

24. Le Beux Y, Hetenyi G Jr, Phillips MJ. Mitochondrial myelin-like figures: a non-specific reactive process of mitochondrial phospholipid membranes to several stimuli. Z. Zellforsch Mikrosk Anat 1969; 99:491-506.

25. Miguet-AlfonsiHYPERLINK "http://www.ncbi.nlm.nih.gov/pubmed?term=Miguet-Alfonsi\%20 C\%5BAuthor\%5D\&cauthor=true\&cauthor_uid=12147305" C, Prunet C, Monier S, Bessède G, LemaireEwing $S$, Berthier $A$, et al. Analysis of oxidative processes and of myelin figures formation before and after the loss of mitochondrial transmembrane potential during 7-beta-hydroxycholesterol and 7-ketocholesterol-induced apoptosis: comparison with various pro-apoptotic chemicals. Biochem Pharmacol 2002; 64:527-41.

26. Lin $\mathrm{CH}$, Chang LW, Wei YH, Wu SB, Yang CS, Chang WH, et al. Electronic microscopy evidence for mitochondria as targets for $\mathrm{Cd} / \mathrm{Se} / \mathrm{Te}$-based quantum dot 705 toxicity in vivo. Kaohsiung $\mathrm{J}$ Med Sci 2012; 28(7 Suppl):S53-62.

27. Alandijany T, Kammouni W, Roy-Chowdhury SL, Fernyhough P, Jackson AC. Mitochondrial dysfunction in rabies virus infection of neurons. J. Neurovirol. 2013; 9:537-49.

28. Robards AW, Wilson AJ. Procedures in electron microscopy. Chichester: John Wiley \& Sons; 1993. p. $5: 1: 54-5: 1: 55$.

29. Castejon OJ. Electron microscopy of myelin figures in normal and pathological tissues. A review. Acta Microscopica 2008; 17:13-19.

30. Schneeberger EE, Lynch RD, Geyer RP. Glutaraldehyde fixation used to demonstrate altered properties of outer mitochondrial membranes in polyunsaturated fatty acid supplemented cells. Exp Cell Res $1976 ; 100: 117-28$. 